Document downloaded from:

http://hdl.handle.net/10251/67246

This paper must be cited as:

Corma Canós, A.; Concepción Heydorn, P.; Boronat Zaragoza, M.; Sabater Picot, MJ.; Navas Escrig, J.; Yacaman, MJ.; Larios, E.... (2013). Exceptional oxidation activity with sizecontrolled supported gold clusters of low atomicity. Nature Chemistry. 5(9):775-781. doi:10.1038/NCHEM.1721.

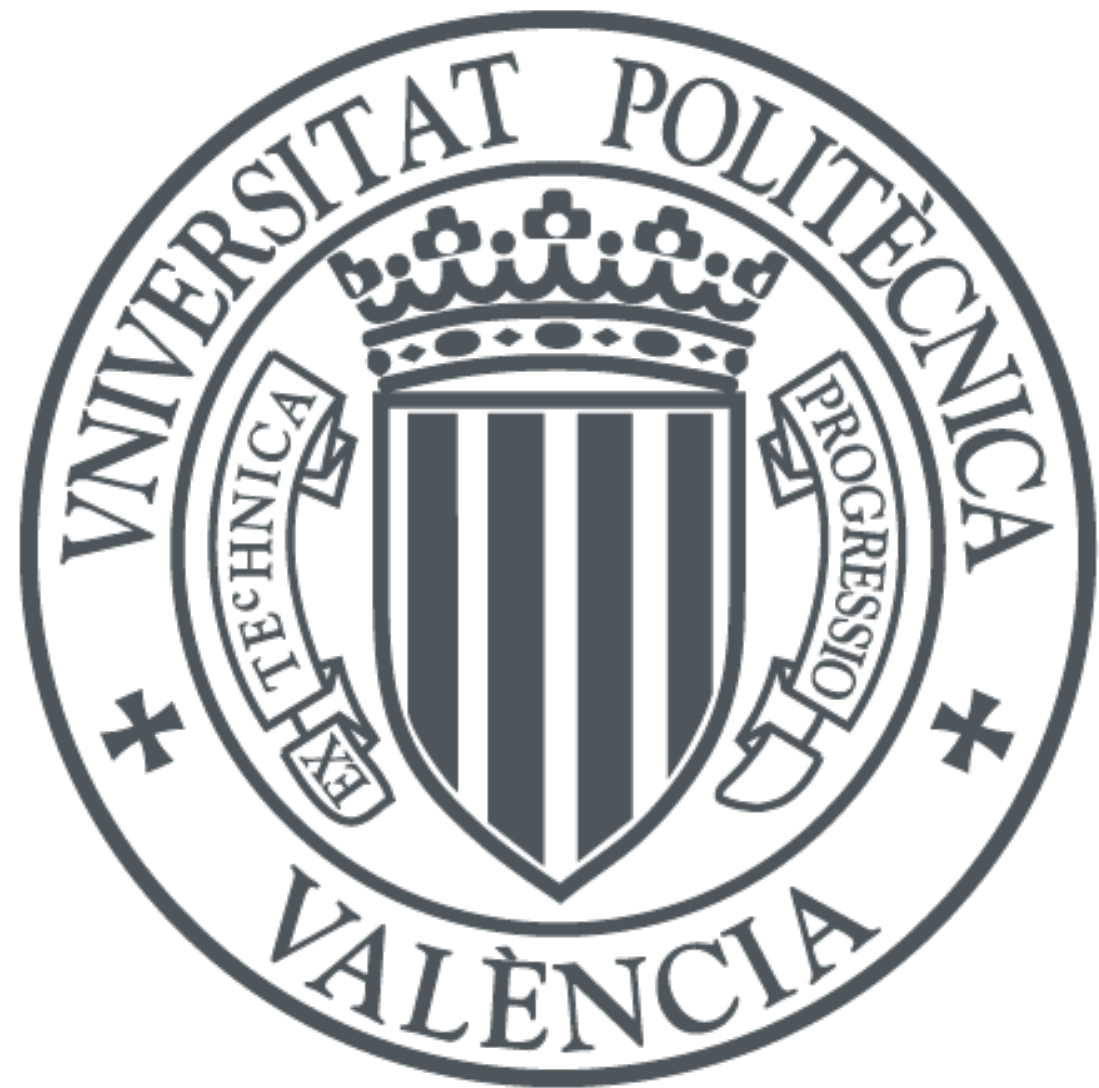

The final publication is available at

https://dx.doi.org/10.1038/nchem.1721

Copyright Nature Publishing Group

Additional Information 


\section{Exceptional oxidation activity with size controlled supported gold clusters of low atomicity}

Avelino Corma, ${ }^{1, *}$ Patricia Concepción, ${ }^{1}$ Mercedes Boronat, ${ }^{1}$ Maria J. Sabater, ${ }^{1}$ Javier Navas, ${ }^{1}$ Miguel José Yacaman, ${ }^{2}$ Eduardo Larios, ${ }^{2,3}$ Alvaro Posadas, ${ }^{2}$ M. Arturo LópezQuintela, ${ }^{4}$ David Buceta, ${ }^{4}$ Ernest Mendoza, ${ }^{5}$ Gemma Guilera, ${ }^{6}$ Alvaro Mayoral $^{7}$

${ }^{1}$ Instituto de Tecnología Química, Universidad Politécnica de Valencia-Consejo Superior de Investigaciones Científicas (UPV-CSIC), Av. de los Naranjos s/n, 46022 Valencia, Spain.

${ }^{2}$ Department of Physics University of Texas at San Antonio One 1604 circle San Antonio Texas 78249 Texas, USA.

${ }^{3}$ On Leave from the University of Sonora.

${ }^{4}$ Dept. Physical Chemistry, Faculty of Chemistry, Lab of Nanotechnology and Magnetism (NANOMAG) Research Technological Institute, University of Santiago de Compostela, E-15782 Santiago de Compostela, Spain.

${ }^{5}$ Grup de Nanomaterials Aplicats, Centre de Recerca en Nanoenginyeria, Universitat Politècnica de Catalunya, c/ Pascual i Vila 15, 08028 Barcelona, Spain.

${ }^{6}$ ALBA Synchrotron, Experiments Division, Crta. BP 1413, de Cerdanyola del Vallès a Sant Cugat del Vallès, 08290 Cerdanyola del Vallès, Barcelona, Spain.

${ }^{7}$ Laboratorio de Microscopias Avanzadas, Instituto de Nanociencia de Aragon, Universidad de Zaragoza, Mariano Esquillor Edificio I+D, 50018, Zaragoza, Spain. 


\section{Summary}

The catalyticic activity of gold depends on particle size, with reactivity increasing as particle diameter decreases. Investigation of the trends in the subnanometer regime, where gold exists as small clusters of a few atoms, is now starting thanks to recent advances in synthesis and characterization techniques. An easy method to prepare isolated gold atoms supported on functionalized carbon nanotubes and their performance in the oxidation of thiophenol with $\mathrm{O}_{2}$ are described. Single gold atoms are not active and they aggregate under reaction conditions into gold clusters of low atomicity, which show a catalytic activity comparable to that sulfhydryl oxidase enzymes. When clusters grow into larger nanoparticles, catalyst activity drops to zero. Theoretical calculations show that gold clusters are able to simultaneously activate thiophenol and $\mathrm{O}_{2}$, while larger nanoparticles become passivated by strongly adsorbed thiolates. The combination of an optimum for reactants activation and product desorption makes gold clusters excellent catalysts.

\section{Main Text}

Gold has attracted wide interest as catalyst in the last years due to its unexpected activity and, specially, to its high selectivity in organic reactions. ${ }^{1-3}$ The catalytic properties of gold depend on several factors that in some cases are intimately related: gold particle size and morphology, metal-oxide support interaction, oxidation state of the active sites, etc. ${ }^{4-8}$ The influence of particle size has been extensively investigated, and a volcano type curve with a maximum in activity at an optimum diameter has been reported for $\mathrm{CO}$ oxidation, ${ }^{7}$ alkane oxidation, ${ }^{9}$ or propene epoxidation with $\mathrm{O}_{2}$ and $\mathrm{H}_{2},{ }^{10}$ while in other cases an exponential increase in activity with decreasing particle size has been observed. ${ }^{5,11,12}$ However, the trends in catalytic activity when the particle diameter 
is smaller than $1 \mathrm{~nm}$ have been little investigated due to the difficulty in achieving a very narrow distribution of cluster sizes and to the detection limit of traditional spectroscopic and microscopic techniques. Recent advances in aberration corrected scanning transmission electron microscopy (STEM) have allowed imaging with atomic resolution. Then, gold atoms in combination with gold clusters and nanoparticles have been detected on gold samples prepared by conventional synthesis procedures, ${ }^{13-15}$ while direct evidence of isolated gold atoms in the absence of clusters or nanoparticles has been recently provided by Gates et al. ${ }^{16,17}$ A pronounced sensitivity to cluster size and charge state has been found when studying the interaction of small molecules with gold atoms and/or clusters, ${ }^{18-22}$ as well as in chemical processes like CO oxidation, ${ }^{13}$ propene epoxidation, ${ }^{23}$ ethylene hydrogenation, ${ }^{24}$ and iodobenzene dissociation. ${ }^{25}$

While it appears that in order to control reactivity, the atomicity control of the gold clusters is crucial, the synthesis of size-selected metal clusters and their deposition over a solid support is a challenging task. ${ }^{26}$ The wet-chemistry methods for preparing supported metal clusters involve the anchoring of well defined precursors to an adequate support, ${ }^{27,28}$ followed by removal of the ligands by post-synthesis treatments, trying to prevent cluster agglomeration during these steps. ${ }^{9,29-31,32}$ Soft landing of monodisperse metal clusters grown in the gas phase and with precise size selection by mass spectrometry is a more straightforward method, but it requires sophisticated equipment, and the scaling up of the process is a major drawback..$^{20,23,33}$

In this work, isolated gold atoms in the absence of gold clusters and/or nanoparticles have been synthesized by a very easy, reproducible and environmental friendly process, and their performance in the aerobic oxidation of thiophenol with $\mathrm{O}_{2}$ has been investigated. The isolated gold atoms initially present in the as-prepared catalyst aggregate into gold clusters of different atomicity under reaction conditions. It 
is clearly shown that, while the activity of single isolated gold atoms and of gold nanoparticles is negligible, atomic aggregates with 5 to 10 atoms either generated under reaction conditions or synthesized separately and deposited on functionalized MWCNTs give turnover frequencies (TOF) as high as $7^{*} 10^{5} \mathrm{~h}^{-1}$, which are of the same order of magnitude than those found with sulfhydryl oxidase enzymes. ${ }^{34,35}$ These clusters finally aggregate into larger and not active nanoparticles. The reaction mechanism has been theoretically studied and it is shown that isolated gold atoms cannot activate $\mathrm{O}_{2}$, while small gold clusters are excellent catalysts for $\mathrm{O}_{2}$ activation and formation of disulfide.

\section{Results and discussion}

Catalyst synthesis and characterization. Isolated gold atoms supported on functionalized multiwalled carbon nanotubes (MWCNTs) have been synthesized by controlling the $\mathrm{pH}$ value of the medium, the concentration of the $\mathrm{HAuCl}_{4}$ precursor, and by introducing sodium citrate that acts as reducing agent and stabilizer, as described in detail in Supplementary Section 1. Cs-corrected high resolution STEM analysis confirms the presence of isolated gold atoms. Figure 1a shows a bright field (BFSTEM) image of sample A containing $0.1 \mathrm{wt} \%$ gold which does not allow to clearly visualize gold atoms supported on the MWCNTs. However, the high-angle annular dark field STEM (HAADF-STEM) image shown in Fig. 1b clearly evidences the presence of isolated atoms (monomers and some dimers), that appear as white dots which correspond to a high $\mathrm{Z}$ element and not to defects or carbon atoms (see Supplementary Fig. S2 and S3).

The chemical nature of these isolated atoms has been investigated by X-ray absorption spectroscopy (XAS) and X-ray photoelectron spectroscopy (XPS). According to XAS measurements, isolated gold atoms are mostly present as cationic 
$\mathrm{Au}^{\mathrm{I}}$ species directly bonded to light elements, most probably $\mathrm{O}$ atoms. The XANES spectrum of sample $\mathrm{A}$ is almost identical to the $\mathrm{Au}$ reference $\left[\left(\mathrm{PPh}_{3}\right) \mathrm{AuCH}_{3}\right]$ spectrum (Figure 1c). Nonetheless, the first peak in the FT of the EXAFS signal appears at slightly lower interatomic distance than the first peak of the reference Au complex due to the different overall nature of the gold ligands (Figure 1d). The coexistence of small gold clusters or other multimetallic complexes cannot be disentangled from the XAS data due to both the intrinsic limitation of the technique and the insufficient data quality for EXAFS quantitative analysis. Although the small peaks at 2.3 and $2.7 \AA$ in Figure $1 \mathrm{~d}$ could indicate the presence of such small gold clusters, they could also be arising from other ligands and structures present in the sample. In agreement with XAS results, XPS analysis performed at $-170{ }^{\circ} \mathrm{C}$ shows the presence of $\mathrm{Au}^{\mathrm{I}}$, with a $\mathrm{Au} 4 \mathrm{f}_{7 / 2}$ binding energy of $85.4 \mathrm{eV}$ (Supplementary Fig. S4). According to Raman and IR analysis, these $\mathrm{Au}^{\mathrm{I}}$ species are stabilized by hydroxyl and citrate or dicarboxyacetone (DCA) ligands (Supplementary Fig. S5 and S6).

Catalytic study of thiophenol oxidation to disulfide. The catalytic behaviour of sample $\mathrm{A}$ in the oxidation of thiophenol to disulfide in the presence of $\mathrm{O}_{2}$ is shown in Fig. 2a. The reaction with this catalyst, containing isolated gold atoms and dimers, presents an initial induction period. After this period, disulfide is formed at a high reaction rate, with $\sim 85 \%$ conversion being attained after 1 hour. The induction period observed with sample A would indicate that the active species are not the isolated gold atoms present in the as-prepared catalyst, but other metal species that are being formed during the reaction. Therefore, the evolution of the gold species present on the catalyst was followed by stopping the reaction at different times, isolating the catalyst, and characterizing the species present by means of HAADF-STEM, XAS and UV/Vis spectroscopies. 
The first catalyst sample extracted from the reaction media (sample B), was taken at $6 \mathrm{~min}$, immediately after the induction period when the catalytic reaction starts with an initial TOF of $1.1 * 10^{5} \mathrm{~h}^{-1}$. The aberration corrected HAADF-STEM image of sample B shows that small clusters with 4-13 gold atoms have been formed, and isolated gold species are now minoritary (Figure 3b and Supplementary Fig. S8). When reaction time proceeds, (sample $\mathrm{C}$ taken at $12 \mathrm{~min}$ ), metal aggregation occurs and gold clusters and nanoparticles can already be observed. After 120 min of reaction (sample D), the activity of the catalyst stops. At this point, gold has aggregated into nanoparticles with diameter $\geq 2 \mathrm{~nm}$, which represent $\sim 90 \%$ of the gold present in the catalyst. Atomic gold cluster distributions calculated on samples A, B and C by analyzing more than 200 gold species are comparatively depicted in Fig. 3e, in which aggregation of the initially isolated gold atoms into clusters and finally nanoparticles is clearly observed. This has also been determined by XAS and UV/Vis measurements (see Supplementary Fig. S13 and S14).

Most importantly is the fact that when sample $\mathrm{B}$, which mainly contains gold clusters with 4-13 atoms, is used as the initial catalyst with fresh feed, no induction period is observed (see Fig. 2b), and the TOF calculated from the slope of conversion versus time, and considering that all atoms in the sample are active, is $0.8^{*} 10^{5} \mathrm{~h}^{-1}$. Meanwhile when catalyst $\mathrm{C}$, which contains $\sim 75 \%$ of gold in the form of nanoparticles and $\sim 20 \%$ as clusters with $4-13$ atoms, is used as fresh catalyst, no induction period is observed, but the calculated TOF decreases to $0.2 * 10^{5} \mathrm{~h}^{-1}$. At last, when sample D mainly containing gold nanoparticles with diameter $\geq 2 \mathrm{~nm}$ is used as fresh catalyst, no activity is observed. The above results clearly suggest that neither isolated gold atoms nor nanoparticles, but gold clusters with 4-13 atoms are the active species for the oxidation of thiophenol. 
To double check this conclusion, isolated gold clusters with 3, 5-7 and 7-10 atoms were prepared separately and deposited on functionalized MWCNTs following the procedure described in Methods and in Supplementary Information. The resultant materials were used as catalysts for thiophenol oxidation, and the results shown in Fig. 4 indicate that with $\mathrm{Au}_{3}$ clusters the reaction still presents an induction period of $5 \mathrm{~min}$, with $\mathrm{Au}_{5-7}$ clusters the induction period is less than $2 \mathrm{~min}$, and with $\mathrm{Au}_{7-10}$ clusters no induction period is observed. In the case of $\mathrm{Au}_{3}$ and $\mathrm{Au}_{5-7}$ clusters the reaction, when starts, is very fast $\left(7.5^{*} 10^{5} \mathrm{~h}^{-1}\right)$ while on $\mathrm{Au}_{7-10}$ the reaction is also very fast $\left(2.8^{*} 10^{5} \mathrm{~h}^{-1}\right)$ but the catalytic activity rapidly decreases and stops at $37 \%$ conversion. From these results we can conclude that the most active gold species for the oxidation of thiophenol to benzene disulfide correspond to small gold clusters containing between 5 and 10 atoms. Indeed, when the TOF values for samples B and C used as fresh catalysts are calculated only on the basis of the clusters with $5-10$ atoms, a TOF of $1.2 * 10^{5} \mathrm{~h}^{-1}$ is obtained on both samples. This value is of the same order of magnitude than for gold prepared in the form of clusters with 5-10 gold atoms. It is interesting to notice that the TOF for the aerobic oxidation of thiols with sulfhydryl oxidase enzymes is similar, and range from $1.2 * 10^{4} \mathrm{~h}^{-1}$ to $1.2 * 10^{5} \mathrm{~h}^{-1} \cdot{ }^{34,35}$ From our experimental results, it is concluded that neither gold atoms nor gold nanoparticles larger than $1 \mathrm{~nm}$ diameter are active for the oxidation of thiophenol. To further confirm this hypothesis, gold nanoparticles of $0.8 \mathrm{~nm}(15-25$ atoms $)$ and $1.2 \mathrm{~nm}$ ( 50 atoms $)$ were supported on the functionalized MWCNTs, and very low or no catalytic activity was observed on these samples (Supplementary Fig. S18 and S19).

The question then becomes: why neither isolated gold atoms nor gold nanoparticles are catalytically active, while gold clusters within 5 and 10 atoms are? To answer this question, the most relevant elementary steps involved in the mechanism of 
thiophenol oxidation to benzene disulfide, i.e., thiophenol dissociation, oxygen activation and S-S bond formation, have been studied by means of DFT calculations on the isolated $\mathrm{Au}^{\mathrm{I}}$ species present in the as-prepared catalyst, as well as on small $\mathrm{Au}_{3}, \mathrm{Au}_{5}$, $\mathrm{Au}_{6}$ and $\mathrm{Au}_{7}$ clusters.

Theoretical study of the reaction mechanism. As described above, the isolated gold species initially present in the catalyst are cationic $\mathrm{Au}^{\mathrm{I}}$ centres coordinated to hydroxyl and carboxy groups from DCA (structure 1 in Fig. 5). Calculations indicate that this species does not interact with $\mathrm{O}_{2}$, (Supplementary Fig. S20) but forms a hydrogen bonded adsorption complex with thiophenol (structure 2 in Fig. 5) that, via proton transfer from $\mathrm{S}$ to the $\mathrm{OH}$ group produces a $\mathrm{H}_{2} \mathrm{O}$ molecule and a system in where the $\mathrm{Ph}-\mathrm{S}$ fragment is directly bonded to the Au centre (structures 3 including $\mathrm{H}_{2} \mathrm{O}$ and 4 after $\mathrm{H}_{2} \mathrm{O}$ desorption). The global process $\mathbf{1} \rightarrow \mathbf{4}$ is almost thermo neutral, and the net charge on the $\mathrm{Au}$ atom decreases from 0.49 in $\mathbf{1}$ to 0.36 in $\mathbf{4}$, reflecting the replacement of the $\mathrm{HO}$ - group by the more electron donating $\mathrm{PhS}$ - ligand. Adsorption of a second thiophenol molecule (complex 5), and subsequent proton transfer from $\mathrm{S}$ to a carboxy $\mathrm{O}$ atom of DCA, results in formation of a highly stable Au-di-thiolate anionic complex interacting with the positively charged DCA fragment (structure 6 in Fig. 5). Attempts to form disulfide from the two thiolate fragments directly bonded to the same Au atom in structure $\mathbf{6}$ always lead to dissociation of the S-S bond and regeneration of the linear $\mathrm{PhS}-\mathrm{Au}^{\mathrm{I}}-\mathrm{SPh}$ complex. The reason is that, in the global process $\mathbf{1} \rightarrow \mathbf{6}$, the two $\mathrm{S}-\mathrm{H}$ bonds of the two reactant thiophenol molecules have been dissociated heterolytically, and the extra electrons are still over the two thiolate fragments (see charge distribution in Fig. 5). The atomic orbital distribution shows that these extra electrons are localized on the S lone pair orbitals leading to strong repulsion between them and to incapacity to form the $\mathrm{S}-\mathrm{S}$ bond. However, if the two extra electrons from the $\mathrm{Au}(\mathrm{S}-\mathrm{Ph})_{2}$ system are 
removed and a globally cationic $\left[\mathrm{Au}(\mathrm{S}-\mathrm{Ph})_{2}\right]^{+}$fragment (structure 7 in Fig. 5) is considered, then the $\mathrm{S}$ atoms bear a small positive charge of 0.10 e each, and there is a reaction pathway leading to formation of disulfide $\mathbf{9}$ via transition state TS8, with an activation barrier of $92 \mathrm{~kJ} / \mathrm{mol}$ and a reaction energy of $38 \mathrm{~kJ} / \mathrm{mol}$. The structures and energies obtained here for disulfide formation or dissociation over $\mathrm{Au}^{+}$cation compare well with those reported for S-S bond dissociation in several L,L-cystine derivatives. ${ }^{36}$ So, it seems that the key point to form the S-S bond is to first remove the two extra electrons from the system, and this should be done by $\mathrm{O}_{2}$. However, neither the initial DCA-Au $-\mathrm{OH}$ complex $\mathbf{1}$ nor intermediates $\mathbf{4}$ and $\mathbf{6}$ formed by replacing the $\mathrm{OH}$ and DCA ligands with thiolate fragments, are able to activate molecular $\mathrm{O}_{2}($ Supplementary Fig. S20). The reason is that the HOMO in structures $\mathbf{1 , 4}$ and $\mathbf{6}$ is mainly a combination of the Au-O and Au-S bonds, and does not allow a good overlap with the LUMO of molecular $\mathrm{O}_{2}$. As a consequence, the degree of $\mathrm{HOMO}_{\mathrm{Au}} \rightarrow \mathrm{LUMO}_{\mathrm{O} 2}$ electron density transfer is small -the calculated charge on $\mathrm{O}_{2}$ in the corresponding $\mathbf{1 - \mathbf { O } _ { 2 }}, \mathbf{4 - \mathbf { O } _ { 2 }}$ and 6-O complexes is less than $0.01 \mathrm{e}-$ and $\mathrm{O}_{2}$ is not activated.

The situation is completely different when small $\mathrm{Au}_{3}, \mathrm{Au}_{5}, \mathrm{Au}_{6}$ and $\mathrm{Au}_{7}$ clusters are considered as active species. Thiophenol adsorbs on all these clusters forming a stable Au--S bond and transferring $\sim 0.2$ e from the $\mathrm{S}$ lone pair to the metal LUMO (Supplementary Fig. S21). $\mathrm{O}_{2}$ interaction with $\mathrm{Au}_{3} \mathrm{Au}_{5}$, and $\mathrm{Au}_{7}$, clusters is also energetically favorable and involves, in most cases, a noticeable activation of the $\mathrm{O}-\mathrm{O}$ bond (Fig. 6a and S21), in agreement with previous studies showing that $\mathrm{O}_{2}$ is activated by small gold clusters with an even number of electrons. ${ }^{18}$ Co-adsorption of thiophenol and $\mathrm{O}_{2}$ is always energetically favorable, and in some cases a synergistic effect leading to a higher degree of $\mathrm{O}_{2}$ activation is observed. The origin of this behaviour lies on the atomic composition of the molecular orbitals of these small clusters (see Fig. 6a) that 
consist of several lobes localized on the low coordinated Au atoms and fully accessible to interaction with $\mathrm{O}_{2}$. This allows a net transfer of electron density from gold to the $\pi^{*}$ oo molecular orbital of $\mathrm{O}_{2}$, leading to its activation.

As shown in Fig. $6 \mathrm{~b}$ for $\mathrm{Au}_{5}$ cluster, which has been experimentally determined as the smallest cluster active for thiophenol oxidation, co-adsorption of thiophenol and $\mathrm{O}_{2}$ on two neighbouring $\mathrm{Au}$ atoms results in formation of a stable intermediate complex 10, in which hydrogen has been transferred from $\mathrm{S}$ to adsorbed $\mathrm{O}_{2}$ without activation barrier, yielding co-adsorbed thiolate and hydroperoxide groups. Adsorption and deprotonation of a second thiophenol molecule yielding $\mathrm{H}_{2} \mathrm{O}_{2}$ co-adsorbed with two thiolate fragments (structure $\mathbf{1 1}$ in Fig. 6b) is also an exothermic and barrier less process. $\mathrm{H}_{2} \mathrm{O}_{2}$ formed according to this mechanism would readily decompose over small $\mathrm{Au}_{\mathrm{n}}$ clusters into two $\mathrm{OH}$ groups that would finally yield $\mathrm{H}_{2} \mathrm{O}$, as previously described. ${ }^{37,38} \mathrm{H}_{2} \mathrm{O}_{2}$ has been experimentally detected as a reactive intermediate species, as well as its final decomposition into $\mathrm{H}_{2} \mathrm{O}$ (details in Supplementary Section 11).

After $\mathrm{H}_{2} \mathrm{O}_{2}$ desorption, the two thiolate fragments that remain adsorbed on the $\mathrm{Au}_{5}$ cluster (structure 12 in Figure $6 \mathrm{~b}$ ) are nearly neutral, bearing each one a net negative charge of -0.05 e and, unlike in $\mathrm{Au}(\mathrm{S}-\mathrm{Ph})_{2}$ system 6, the HOMO of structure 12 is not only localized on the $\mathrm{S}$ atoms but it also involves important contributions from the phenyl rings and the Au atoms (Figure 6c). Therefore, there is not electrostatic repulsion between the two S atoms, and the S-S bond can be formed via transition state TS13, with the process involving also an important rearrangement of the gold cluster geometry. The intrinsic activation energy obtained for this elementary step is 142 $\mathrm{kJ} / \mathrm{mol}$, but the high exothermicity of all previous adsorption steps makes the global process energetically accessible. Thus, the main difference between isolated $\mathrm{Au}^{\mathrm{I}}$ species and $\mathrm{Au}_{\mathrm{n}}$ clusters is the ability of the last ones to transfer electrons from thiolate 
fragments to $\mathrm{O}_{2}$, making possible the formation of the $\mathrm{S}-\mathrm{S}$ bond, as it happens with sulfhydryl oxidase enzymes.

A decrease in the activity for disulfide formation with larger particles is experimentally observed, together with a poisoning of the gold nanoparticles with thiolate groups. This is explained by the lower concentration of active Au atoms accessible to reactants as particles grow, and by the strong $\mathrm{Au}-\mathrm{S}$ interaction, that leads to formation of very stable linear RS-Au-SR units or "staple" motifs and passivation of the gold NP surface (see Fig. 6d). ${ }^{39,40}$

\section{Conclusions}

We have succeeded in preparing single isolated gold atoms on MWCNTs, and have studied their performance in the oxidation of thiophenol to disulfide by $\mathrm{O}_{2}$. Following the evolution of the catalyst during the reaction we have shown that isolated atoms are not active and they aggregate under reaction conditions into gold clusters of low atomicity. Gold clusters with 5 to 10 atoms are extremely active for the reaction, with TOF in the order of $10^{5} \mathrm{~h}^{-1}$. Finally, when clusters grow into nanoparticles of diameter $\geq$ $1 \mathrm{~nm}$, the catalyst activity drops to zero. Theoretical calculations show that only gold clusters of low atomicity are able to simultaneously adsorb and activate thiophenol and $\mathrm{O}_{2}$, while the strong Au-S interaction in $1 \mathrm{~nm}$ gold nanoparticles leads to formation of very stable RS-Au-SR units that impede the reaction to proceed. The combination of reactant activation and desorption facilities makes the cluster successful for this oxidation reaction. 


\section{Methods}

Synthesis. Au/MWCNTs material was synthesized with some modifications of the general procedure reported in ref. ${ }^{41}$ and described in detail in Supplementary Section 1. Isolated gold clusters with 3, 5-7 and 7-10 atoms were synthesized using modifications of the electrochemical method previously reported for nanoparticles ${ }^{42}$ and described in detail in Supplementary Section 8. Once synthesized, the gold clusters were supported by a wet impregnation procedure on carbon nanotubes which had been previously wrapped with the polyelectrolyte polyallylamine hydrochloride (PAH). A 0,015wt\% gold loading was used. The atomicity of the gold clusters was checked by UV/Vis, photoluminescence emission and mass spectroscopy as described in Supplementary Section 8 .

HR-STEM. The samples were characterized in a JEOL JEMARM200F electron microscope operated at $80 \mathrm{kV}$ (electron dose of $1.4 \times 10^{3} \mathrm{e}^{-/}$angstrom $^{2}$ ). The samples were dispersed in ethanol and a drop of this suspension was deposited onto a holey carbon grid, and immediately allowed to dry at room temperature. STEM images were simultaneously recorded in both the HAADF and BF modes. The probe correction was performed with a CEOS corrector obtaining a twelve-fold Ronchigram with a flat area of $\sim 40 \mathrm{mrad}$. The probe size was $0.1 \mathrm{~nm}$, and dwell time was $20 \mathrm{msec}$ per pixel. The images were registered with a condenser lens aperture of 30 microns (convergence angle $25 \mathrm{mrad}$ ), the HAADF collection angle ranges from 45 to $180 \mathrm{mrad}$, the spot size used was $\sim 35 \mathrm{pA}$.

Catalytic Experiments. The catalytic experiments were carried out at $25^{\circ} \mathrm{C}$ and $5 \mathrm{bar} \mathrm{O}_{2}$ using a glass reactor equipped with a manometer and a micro-sampling system which allows extracting reaction samples at regular reaction times. Reaction samples were analyzed by gas chromatography using a HP-5 capillary column (5\% phenyl, 30m x 
$0.25 \mathrm{~m}$ ) and products identified by GC-MS, using a Fison GC 8000 gas chromatograph equipped with DB5 capillary column with a mass spectrometry detector (Fisons MD 800 quadrupole detector). Under typical reaction conditions $1 \mathrm{mmol}$ thiophenol, $20 \mu \mathrm{L}$ dodecane as internal standard, $1.2 \mathrm{~mL}$ dry toluene and $\sim 4 \mathrm{mg}$ of catalyst were charged into the reactor that was purged with oxygen three times and then pressurized with 5 bar of $\mathrm{O}_{2}$. Upon stopping the reaction, the reactor was degassed slowly and the catalyst separated by centrifugation. For catalyst reuse, the reaction was stopped at specific times and the catalyst removed from the liquid by centrifugation. These catalyst samples were used to carry out a new reaction under the same initial conditions.

Control experiments were done in absence of $\mathrm{O}_{2}$. Working at 5 bar of $\mathrm{N}_{2}$ no catalytic activity was obtained, evidencing that $\mathrm{O}_{2}$ is required for catalytic performance. On the other hand, leaching of gold ions form the catalyst toward the reaction solution was tested by filtering the catalysts from the solution and following the activity of the liquid. No catalytic activity was detected in absence of the catalyst, and therefore any contribution of homogeneous catalysis can be neglected.

Calculation of turnover frequencies. Turnover frequencies (TOF) were calculated by dividing initial reaction rates (measured in molecules of disulfide formed per hour) by the number of active gold atoms in the catalyst. It was initially assumed that all gold atoms in the size selected clusters with 3, 5-7 and 7-10 gold atoms and in samples B and $\mathrm{C}$ are active. Then, a second value was calculated for samples $\mathrm{B}$ and $\mathrm{C}$ assuming that only the gold atoms in clusters containing from 5 to 10 atoms are active, as described in the main text.

Computational details. DFT calculations were performed using the hybrid B3LYP ${ }^{43,44}$ functional as implemented in the Gaussian03 computer program. ${ }^{45}$ The standard 6$311 \mathrm{G}(\mathrm{d}, \mathrm{p})$ basis set was used for S, C, O, H and Na atoms, ${ }^{46,47}$ while the effective core 
potential LANL2DZ basis set was chosen for Au atoms. ${ }^{48}$ Atomic charges were calculated using the NBO approach. ${ }^{49}$ The geometries of all structures involved in the mechanism were fully optimized without any restriction, except for the $\mathrm{Au}_{13}$ model, in which only one Au atom in the system was allowed to move to avoid artificial distortion of the nanoparticle. Transition states were characterized by the presence of a single imaginary frequency associated to the reaction coordinate.

\section{References}

${ }^{1}$ Hughes, M. D., Xu, Y. J., Jenkins, P., McMorn, P., Landon, P., Enache, D. I., Carley, A. F., Attard, G. A., Hutchings, G. J., King, F., Stitt, E. H., Johnston, P., Griffin, K. \& Kiely, C. J. Tunable gold catalysts for selective hydrocarbon oxidation under mild conditions. Nature 437, 1132-1135 (2005).

${ }^{2}$ Hashmi, A. S. K. \& Hutchings, G. J. Gold catalysis. Angew. Chem. Int. Ed. 45 78967936 (2006).

${ }^{3}$ Corma, A. \& Garcia, H. Supported gold nanoparticles as catalysts for organic reactions. Chem. Soc. Rev. 37, 2096-2126 (2008).

${ }^{4}$ Haruta, M. Size- and support-dependency in the catalysis of gold. Catal. Today 36, 153-166 (1997).

${ }^{5}$ N. López, T. V. J. Janssens, B. S. Clausen, Y. Xu, M. Mavrikakis, T. Bligaard J. K. Nørskov, J. K. On the origin of the catalytic activity of gold nanoparticles for lowtemperature CO oxidation. J. Catal. 223, 232-235 (2004).

${ }^{6}$ Hutchings, G. J. Catalysis by gold. Catal. Today, 100, 55-61 (2005).

${ }^{7}$ Chen, M. S. \& Goodman, D. W. Catalytically active gold: from nanoparticles to ultrathin films. Acc. Chem. Res. 39, 739-746 (2006). 
${ }^{8}$ Risse, Th., Shaikhutdinov, Sh., Nilius, N., Sterrer, M. \& Freund, H. J. Gold supported on thin oxide films: from single atoms to nanoparticles. Acc. Chem. Res. 41, 949-956 (2008).

${ }^{9}$ Liu, Y., Tsunoyama, H., Akita, T., Xie, S. \& Tsukuda, T. Aerobic oxidation of cyclohexane catalyzed by size-controlled Au clusters on hydroxyapatite: size effect in hte sub-2nm regime. ACS Catal. 1, 2-6 (2011).

${ }^{10}$ Huang, J., Lima, E., Akita, T., Guzman, A., Qi, C., Takei, T. \& Haruta, M. Propene epoxidation with $\mathrm{O}_{2}$ and $\mathrm{H}_{2}$ : identification of the most active gold clusters. J. Catal. 278, 8-15 (2011).

${ }^{11}$ Haruta, M., Tsubota, S., Kobayashi, T., Kageyama, H., Genet, M. J. \& Delmon, B. Low-temperature oxidation of $\mathrm{CO}$ over gold supported on $\mathrm{TiO}_{2}, \alpha-\mathrm{Fe}_{2} \mathrm{O}_{3}$, and $\mathrm{Co}_{3} \mathrm{O}_{4} . J$. Catal. 144, 175-192 (1993).

${ }^{12}$ Tsunoyama, H., Ichikuni, N., Sakurai, H. \& Tsukuda, T. Effect of electronic structures of Au clusters stabilized by poly(N-vinyl-2-pyrrolidone) on aerobic oxidation catalysis. J. Am. Chem. Soc. 131, 7086-7093 (2009).

${ }^{13}$ Herzing, A. A., Kiely, C. J., Carley, A. F., Landon, P. \& Hutchings, G. J. Identification of active gold nanoclusters on iron oxide supports for $\mathrm{CO}$ oxidation. Science 321, 1331-1332 (2008).

${ }^{14}$ Lupini A. R., Veith, G. M., Dudney, J. \% Pennycook, S. J. Understanding catalyst stability through aberration-corrected STEM. Microscopy and Microanalysis 15, 14081409 (2009). J. Phys. Chem. C 2009, 113, 269-280.

${ }^{15}$ Allard, L. F., Borisevich, A., Deng, W., Si, R., Flytzani-Stephanopoulos, M. \& Overbury, S. H. Evolution of gold structure during thermal treatment of $\mathrm{Au} / \mathrm{FeOx}$ catalysts revealed by aberration-corrected electron microscopy. J. Electron Microsc. 58, 199-212 (2009). 
${ }^{16}$ Uzun, A., Ortalan, V., Hao, Y., Browning, N. D. \& Gates, B. C. Imaging gold atoms in site-isolated MgO-supported mononuclear gold complexes. J. Phys. Chem. C 113, 16847-16849 (2009).

${ }^{17}$ Lu, J., Aydin, C., Browning, N. D. \& Gates, B. C. Imaging isolated gold atom catalytic sites in zeolite NaY. Angew. Chem. Int. Ed. 51, $5842-5846$ (2012).

${ }^{18}$ Yoon, B., Häkkinen, H. \& Landman, U. Interaction of $\mathrm{O}_{2}$ with gold clusters: molecular and dissociative adsorption. J. Phys. Chem. A 107, 4066-4071 (2003). ${ }^{19}$ Lang, S. M., Bernhardt, T. M., Barnett, R. N., Yoon, B. \& Landman, U. Hydrogenpromoted oxygen activation by free gold cluster cations. J. Am. Chem. Soc. 131, 89398951 (2009).

${ }^{20}$ Hagen, J., Socaciu, L. D., Elijazyfer, M., Heiz, U., Bernhardt, T. M. \& Wöste, L. Coadsorption of $\mathrm{CO}$ and $\mathrm{O}_{2}$ on small free gold cluster anions at cryogenic temperatures: Model complexes for catalytic CO oxidation. Phys. Chem. Chem. Phys. 4, 1707-1709 (2002).

${ }^{21}$ Molina, L. M., Lesarri, A. \& Alonso, J. A. New insights on the reaction mechanism for CO oxidation on Au catalysts. Chem. Phys. Lett. 468, 201-204 (2009).

${ }^{22}$ Joshi, A. M., Delgass, W. N. \& Thomson, K. T. Comparison of the catalytic activity of $\mathrm{Au}_{3}, \mathrm{Au}_{4}{ }^{+}, \mathrm{Au}_{5}$ and $\mathrm{Au}_{5}{ }^{-}$in the gas-phase reaction of $\mathrm{H}_{2}$ and $\mathrm{O}_{2}$ to form hydrogen peroxide: a Density Functional Theory investigation. J. Phys. Chem. B 109, 22392$22406(2005)$.

${ }^{23}$ Lee, S., Molina, L. M., López, M. J., Alonso, J. A., Hammer, B., Lee, B., Seifert, S., Winans, R. E., Elam, J. W., Pellin, M. J. \& Vajda, S. Selective propene epoxidation on immobilized $\mathrm{Au}_{6-10}$ clusters: the effect of hydrogen and water on activity and selectivity. Angew. Chem. Int. Ed. 48, 1467-1471 (2009). 
${ }^{24}$ Guzman, J. \& Gates, B. C. Structure and reactivity of a mononuclear gold-complex catalyts supported on magnesium oxide. Angew. Chem. Int. Ed. 42, 690-693 (2003). ${ }^{25}$ Robinson, P. S. D., Khairallah, G. N., da Silva, G., Lioe, H. \& O’Hair, R. A. J. Goldmediated C-I bond activation of iodobenzene. Angew. Chem. Int. Ed. 51, 3812-3817 (2012).

${ }^{26}$ C. J. Jia, C. J. \& Schüth, F. Colloidal metal nanoparticles as a component of designed catalyst. Phys. Chem. Chem. Phys. 13, 2457-2487 (2011).

${ }^{27}$ Tran, M. L., Zvyagin, A. V. \& Plakhotnik, T. Synthesis and spectroscopic observation of dendrimer-encapsulated gold nanoclusters. Chem. Commun. 2400-2401 (2006).

${ }^{28}$ Ledo-Suárez, A., Rivas, J., Rodriguez-Abreu, C. F., Rodriguez, M. J., Pastor, E., Hernandez-Creus, A., Oseroff, S. B. \& Lopez-Quintela, M. A. Facile synthesis of stable subnanosized silver clusters in microemulsions. Angew. Chem. Int. Ed. 46, 8823- 8827 (2007).

${ }^{29}$ Turner, M., Golovko, V. B., Vaughan, O. P. H., Abdulkin, P., Berenguer-Murcia, A., Tikhov, M. S., Johnson, B. F. G. \& Lambert, R. M. Selective oxidation with dioxygen by gold nanoparticle catalysts derived from 55-atom clusters. Nature 454, 981-983 (2008).

${ }^{30}$ Y. M. Liu, H. Tsunoyama, T. Akita, T. Tsukuda, Chem. Commun. 2010, 46, 550-552.

${ }^{31}$ Shichibu, Y. \& Konishi, K. HCl-induced nuclearity convergence in diphosphineprotected ultrasmall gold clusters: a novel synthetic route to "magic-number" $\mathrm{Au}_{13}$ clusters. Small 6, 1216-1220 (2010).

${ }^{32}$ Xie, S., Tsunoyama, H., Kurashige, W., Negishi, Y. \& Tsukuda, T. Enhancement in aerobic alcohol oxidation catalysis of $\mathrm{Au}_{25}$ clusters by single $\mathrm{Pd}$ atom doping. ACS Catal. 2, 1519-1523 (2012). 
${ }^{33}$ Sanchez, A., Abbet, S., Heiz, U., Scheiner, W. D., Häkkinen, H., Barnett, R. N. \& Landman, U. When gold is not noble: Nanoscale gold catalysts. J. Phys. Chem. A 103, 9573-9578 (1999).

${ }^{34}$ Hoober, K. L. \& Thorpe, C. Egg white sufhydryl oxidase: kinetic mechanism of the catalysis of disulfide bond formation. Biochemistry 38, 3211-3217 (1999).

${ }^{35}$ Jaje, J., Wolcott, H. N., Fadugba, O., Cripps, D., Yamg, A. J., Mather, I. H. \& Thorpe, C. A flavin-dependent sulfhydryl oxidase in bovine milk. Biochemistry 46, 13031-13040 (2007).

${ }^{36}$ Dumont, E., Michel, C. \& Sautet, P. Unraveling gold(I)-specific action towards peptidic disulfide cleavage: a DFT investigation. ChemPhysChem 12, 2596-2603 (2011).

${ }^{37}$ Barton, D. G. \& Podkolzin, S. G. Kinetic study of a direct water synthesis over silicasupported gold nanoparticles. J. Phys. Chem. B 109, 2262-2274 (2005).

${ }^{38}$ Ntainjua, E. N., Edwards, J. K., Carley, A. F., Lopez-Sanchez, J. A., Moulijn, J. A., Herzing, A. A., Kiely, C. J. \&. Hutchings, G. J. The role of the support in achieving high selectivity in the direct formation of hydrogen peroxide. Green Chemistry $\mathbf{1 0}$, 1162-1169 (2008).

${ }^{39}$ Jadzinsky, P. D., Calero, G., Ackerson, C. J., Bushnell, D. A. \& Kornberg, R. D. Structure of a thiol monolayer-protected gold nanoparticle at 1.1 Á resolution. Science 318, 430-433 (2007).

${ }^{40}$ H. Häkkinen, H. The gold-sulfur interface at the nanoscale. Nature Chem. 4, 443-455 (2012).

${ }^{41}$ Alves, L., Ballesteros, B., Boronat, M., Cabrero-Antonino, J. R., Concepción, P., Corma, A., Correa-Duarte, M. A. \& Mendoza, E. Synthesis and stabilization of 
subnanometric gold oxide nanoparticles on multiwalled carbon nanotubes and their catalytic activity. J. Am. Chem. Soc. 133, 10251-10261 (2011).

${ }^{42}$ Santiago-González, B., Rodríguez, M.J., Blanco, M.C., Rivas, J., López-Quintela, M.A. \& Gaspar-Martinho, J.M. One Step Synthesis of the Smallest Photoluminescent and Paramagnetic PVP-Protected Gold Atomic Clusters. Nano Letters 10, 4217-4221 (2010).

${ }^{43}$ Becke, A. D. Density-functional thermochemistry. III. The role of exact exchange. $J$. Chem. Phys., 98, 5648-5652 (1993).

${ }^{44}$ Lee, C., W. Yang, W. \& Parr, R. G. Development of the Colle-Salvetti correlation energy formula into a functional of the electron density. Phys. Rev. B, 37, 785-789 (1988).

${ }^{45}$ M. J. Frisch, G. W. Trucks, H. B. Schlegel, et al., Gaussian 03, Revision B.04, Gaussian, Inc. Pittsburgh, PA, 2003.

${ }^{46}$ McLean A. D. \& Chandler G. S. Contracted Gaussian basis sets for molecular calculations. I. Second row atoms, Z=11-18. J. Chem. Phys., 72 5639-5648 (1980).

${ }^{47}$ Raghavachari, K., J. S. Binkley, J. S., R. Seeger, R. \&. Pople, J. A. Self-consistent molecular orbital methods. XX. A basis set for correlated wave functions. J. Chem. Phys., 72 650-654 (1980).

${ }^{48}$ Hay P. J. \& Wadt, W. R. Ab initio effective core potentials for molecular calculations. Potentials for the transition metal atoms Sc to Hg. J. Chem. Phys. 82, 270-283 (1985). ${ }^{49}$ Reed, A. E., Weinstock, R. B. \& Weinhold, F. Natural population analysis. J. Chem. Phys. 83, 735-747 (1985). 


\section{Acknowledgements}

Financial support from the Spanish Science and Innovation Ministry (Consolider Ingenio 2010-MULTICAT CSD2009-00050, Subprograma de apoyo a Centros y Universidades de Excelencia Severo Ochoa SEV 2012 0267, MAT2011-28009 and MAT2010-20442 projects) and Xunta de Galicia (Grupos Ref.Comp.2010/41) is acknowledged. M.J.Y. and E.L. would like to acknowledge the support of the National Centre for Research Resources (5 G12RR013646-12) and the National Institute on Minority Health and Health Disparities (G12MD007591) from the National Institutes of Health and to the NSF for support with grants DMR-1103730, and PREM: NSF PREM Grant \# DMR 0934218. We also Acknowledge the support of the CONACYT. J.N. expresses his gratitude to Consejo Superior de Investigaciones Científicas for a JAE fellowship.

\section{Author Contributions}

A.C. conceived, designed and directed the study and the analysis and interpretation of results. P.C. performed catalyst synthesis, characterization and testing. E.M. participated in catalyst synthesis. M. J. S. and J. N. carried out catalyst testing. M.B. designed and carried out the theoretical study. M.J.Y., E. L. and A. P. performed the HR-STEM characterization. A.L.Q. and D.B. synthesized and characterized the isolated size-controlled clusters. G.G. did the XAS measurements. A.M. collaborated in HRSTEM characterization. The manuscript was written by P.C., M.B. and A.C.

\section{Additional Information}

The authors declare no competing financial interests. Supplementary Information accompanies this paper at www.nature.com/naturechemistry. Reprints and permissions 
information is available at www.nature.com/reprintsandpermissions. Correspondence and requests for materials should be addressed to A. C. acorma@itq.upv.es.

\section{Figure Legends}

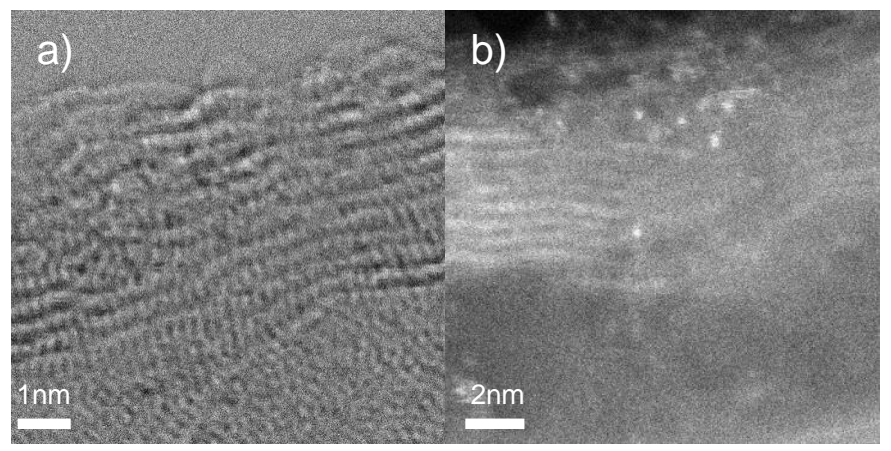

c)

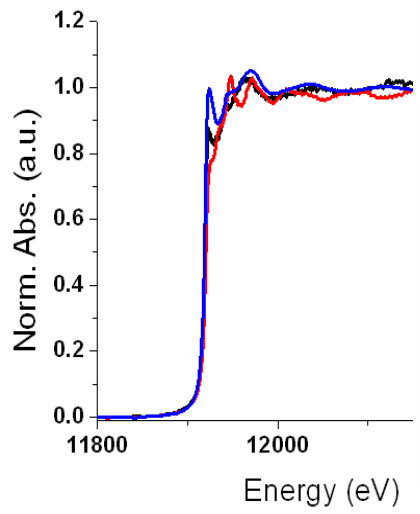

d)

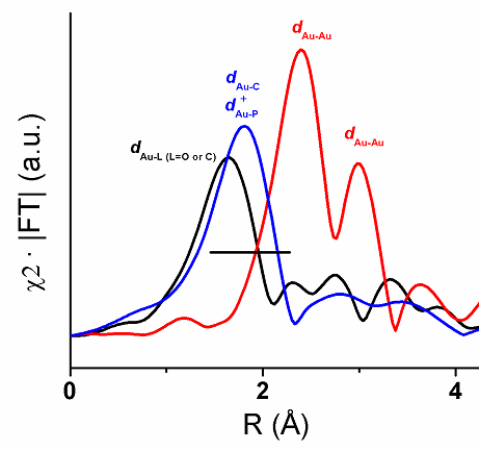

Figure 1. Identification of isolated gold atoms. Isolated gold atoms supported on functionalized multiwalled carbon nanotubes have been synthesized (sample A) and their presence confirmed by Cs-corrected high resolution STEM analysis and XAS analysis. a, BF-STEM image of sample A, which does not allow to clearly visualize gold atoms supported on the MWCNTs. b, HAADF-STEM image of sample A clearly showing the presence of isolated atoms (monomers and some dimers), that appear as white dots on the carbon nanotube. $\mathbf{c}, \mathbf{d}, \mathrm{XAS}$ at the $\mathrm{Au} \mathrm{L}_{3}$-edge (c) and EXAFS Fourier transforms (d) of supported Au NP of $4 \mathrm{~nm}$ (red line), of the reference $\left(\mathrm{PPh}_{3}\right) \mathrm{AuCH}_{3}$ (blue line), and of sample A (black line). The similarity between the blue and black 
lines indicates that in the as-prepared catalyst gold is mostly present as isolated cationic $\mathrm{Au}^{\mathrm{I}}$ species directly bonded to light elements.

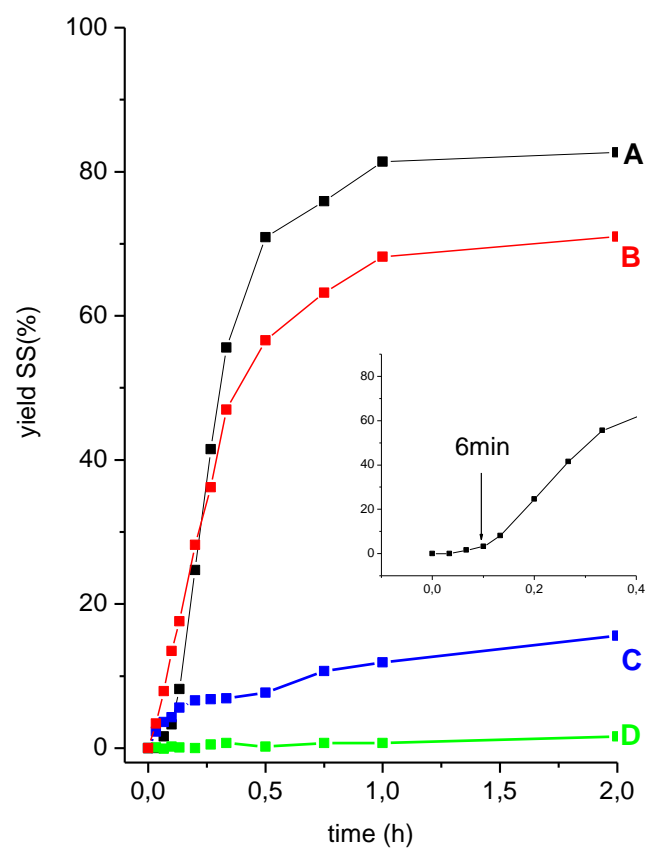

Figure 2. Oxidation of thiophenol to disulfide in the presence of $\mathbf{O}_{2}$. Single isolated gold atoms (sample A) are not active in the oxidation of thiophenol showing an induction period of $6 \mathrm{~min}$, which indicate that other metal species are being formed during reaction. The evolution of the gold species was followed by stopping the reaction at different times. The catalyst samples (sample B, C, D taken at 6, 12, 120 min of reaction of sample A) were used to carry out a new reaction under the same conditions. The yield to disulfide with reaction time using as catalyst samples A, B, C, and D is shown. Inset: zoom of sample A in the beginning of the reaction showing the induction period. 

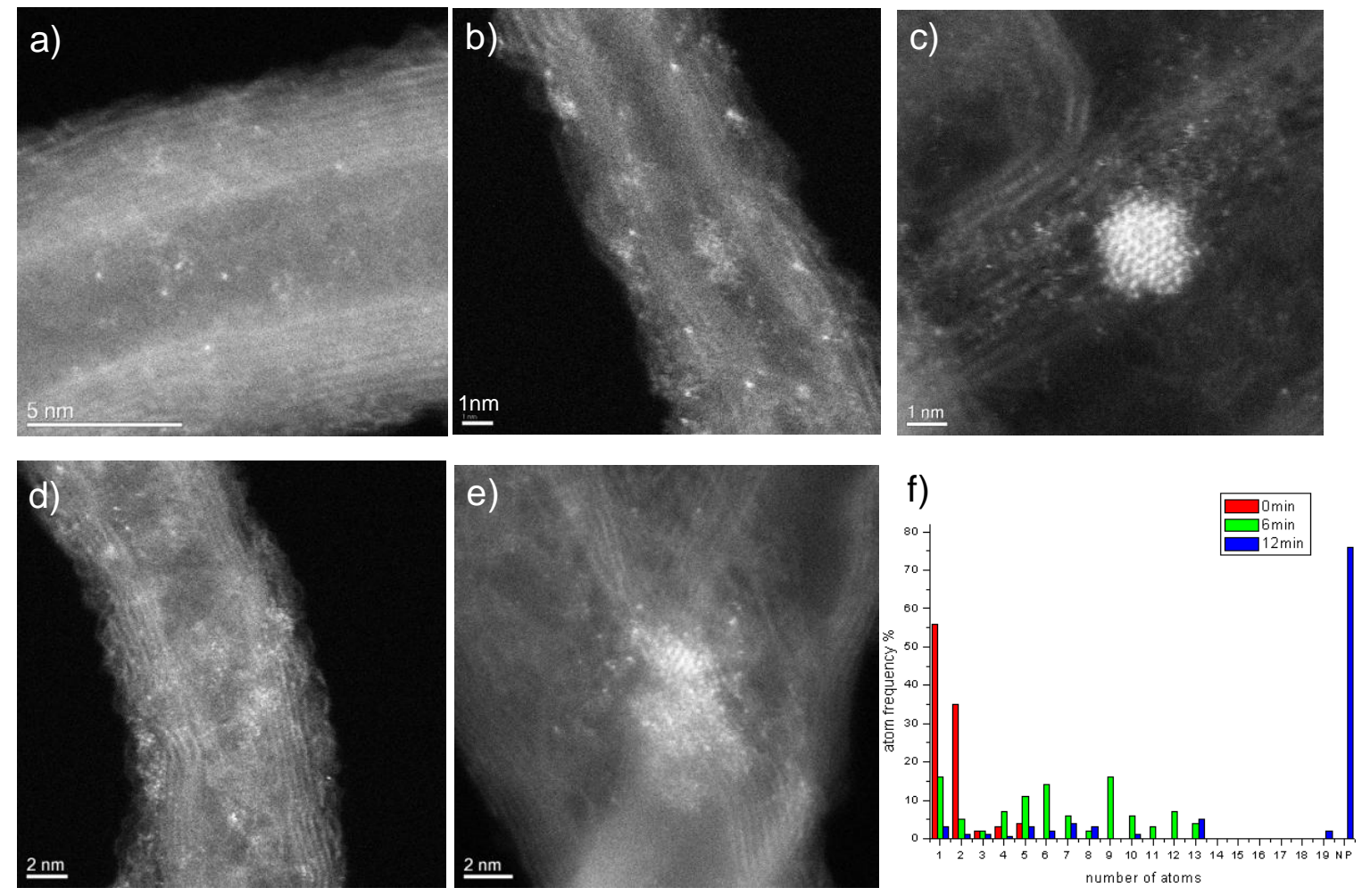

Figure 3. Evolution of the gold species present on the catalyst. The evolution of gold species present on the catalyst was followed by stopping the reaction at different times, isolating the catalyst and characterising it by means of HAADF-STEM. a, Isolated gold atoms present on the as-prepared catalyst, sample A. b, Image of sample B taken at 6 min reaction, showing the presence of small clusters with 4-13 atoms. c, d, Two different images of sample $\mathrm{C}$ taken at 12 min reaction, in which both small clusters and some large nanoparticles can be observed. e, In sample D, taken after 120 min of reaction, most gold has aggregated into nanoparticles with diameter $\geq 2 \mathrm{~nm}$. Additional HAADF-STEM images at different magnifications are included as Supplementary Figures S9-S12. f, Comparison of the atomic gold cluster distributions calculated on samples A, B and C by analyzing more than 200 gold species. 


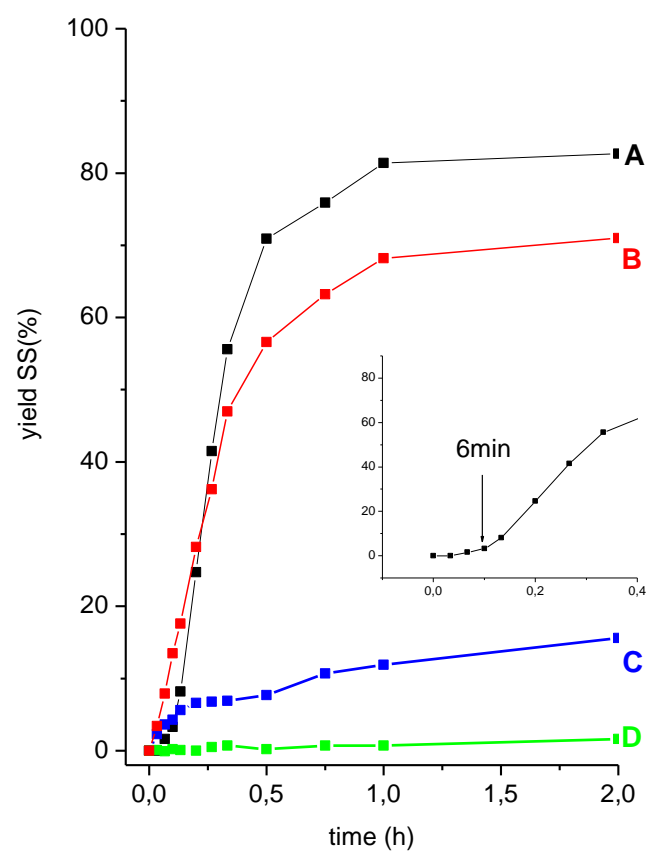

Figure 4. Oxidation of thiophenol to disulfide in the presence of $\mathrm{O}_{2}$ catalysed by size selected gold clusters. Gold clusters of $A_{3}, A u_{5-7}$ and $A u_{7-10}$ were synthesised by an electrochemical method and deposited on functionalized MWCNT. Their activity was tested in the oxidation of thiophenol. Yield to disulfide with reaction time using $\mathrm{Au}_{3}, \mathrm{Au}_{5-7}$ and $\mathrm{Au}_{7-10}$ gold clusters supported on MWCNs as catalyst. 

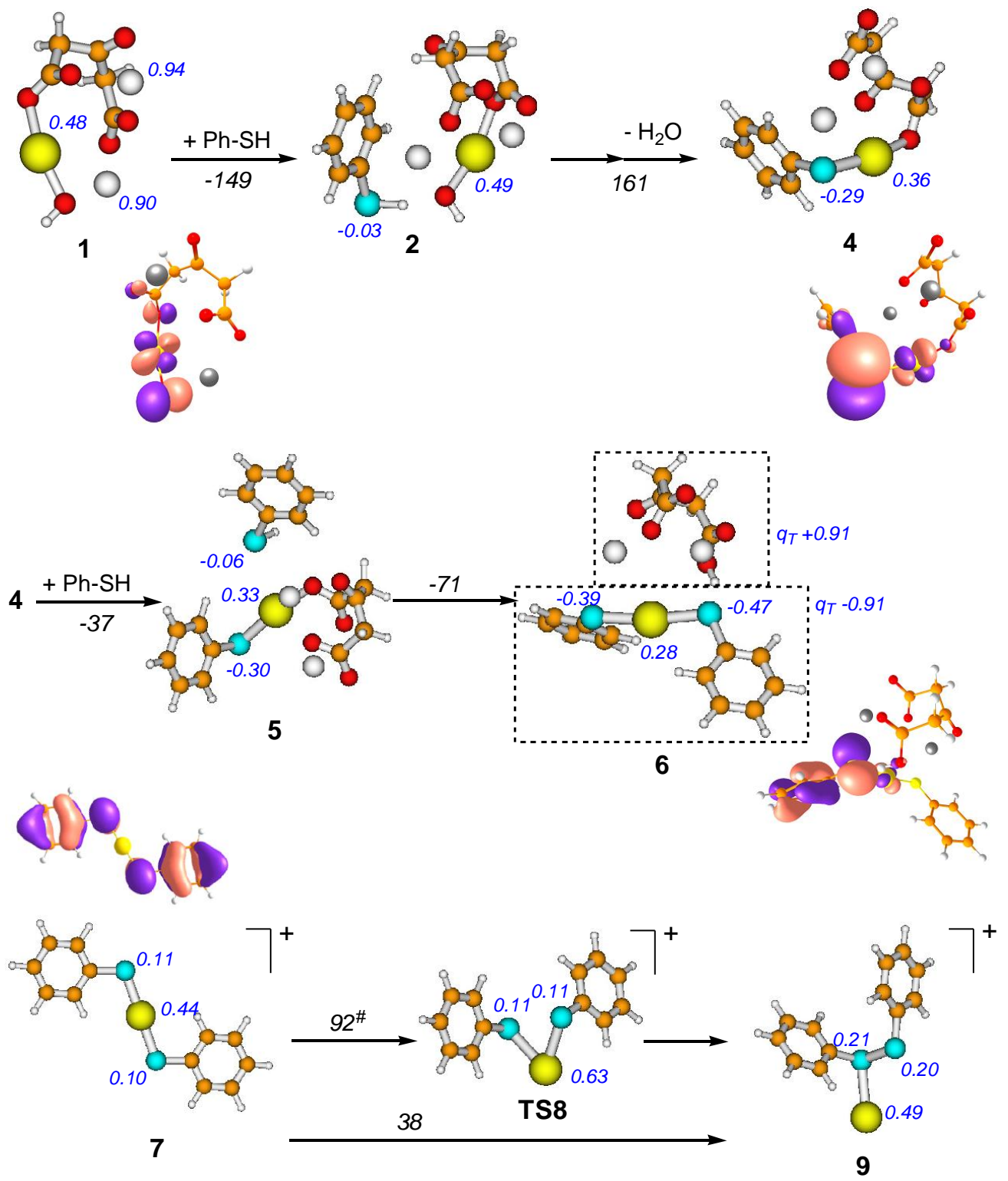

Figure 5. Structures involved in the mechanism of disulfide formation catalyzed by

Au' ' species. Gold, Sulfur, Carbon, Oxygen and Hydrogen atoms are depicted in golden, blue, orange, red and white, respectively. The italic numbers that appear beside the arrows are the reaction and activation (denoted with \#) energies in $\mathrm{kJ} / \mathrm{mol}$ calculated for each elementary step. The numbers in blue that appear next to various selected atoms are net atomic charges, in units of e. In structure $\mathbf{6}, \mathrm{q}_{\mathrm{T}}$ is the total charge on each of the two fragments framed by dotted lines. TS 8 is a transition state structure. Atomic distribution of the highest occupied molecular orbitals (HOMOs) of selected structures is also depicted. 
a)

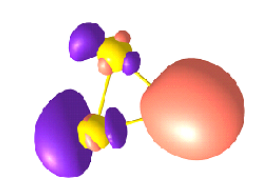

$\mathrm{Au}_{3}$

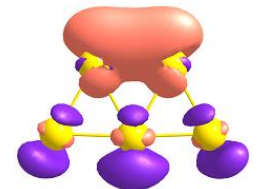

$\mathrm{Au}_{5}$

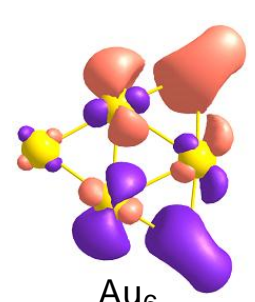

$\mathrm{Au}_{6}$
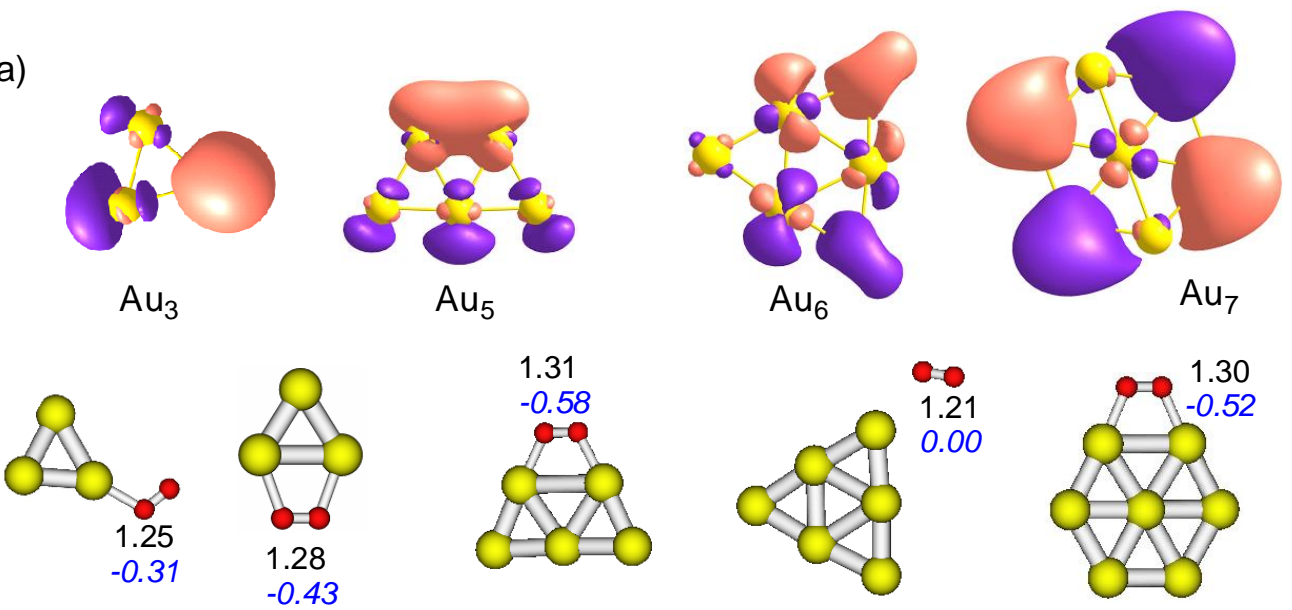

b)

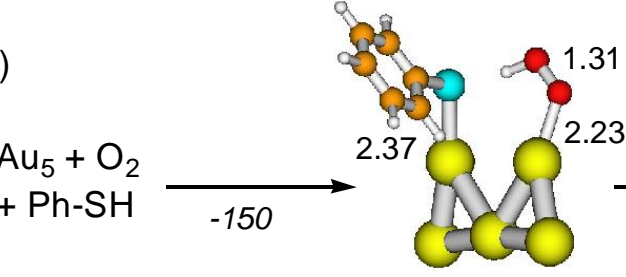

10
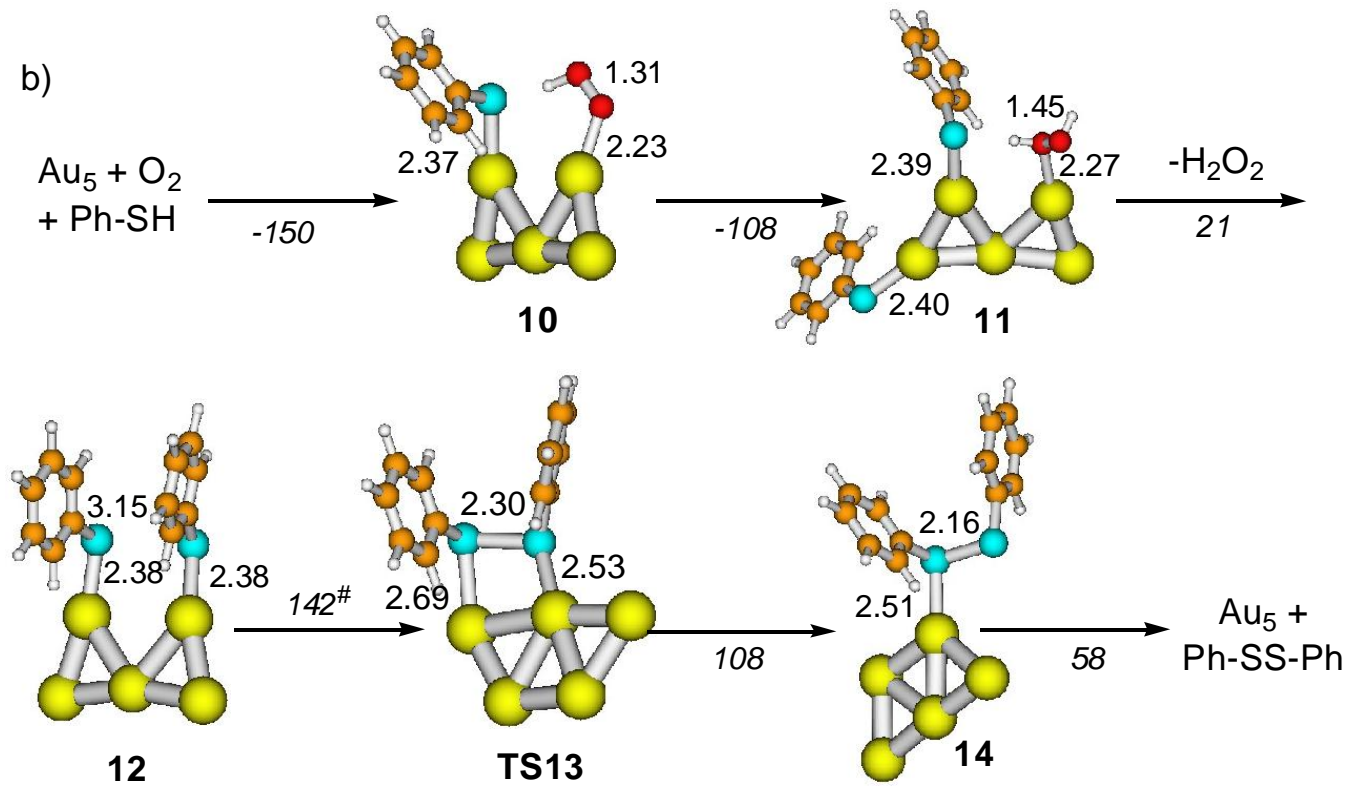

c)

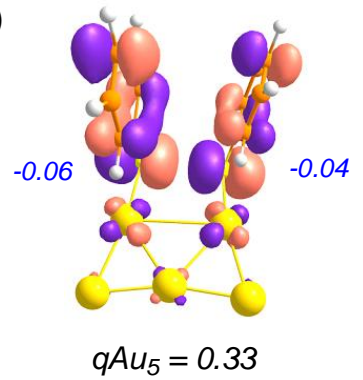

d)

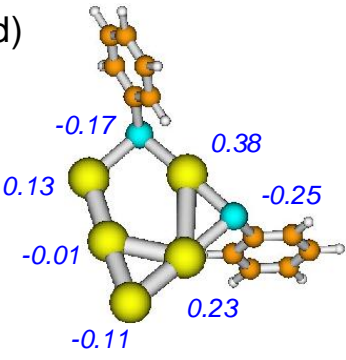

$q A u_{5}=0.62$

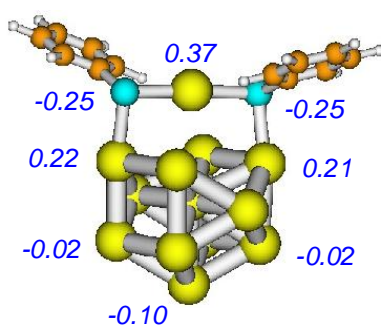

$q A u_{13}=0.71$

Figure 6. Reactivity of gold clusters of low atomicity. a, Atomic distribution of the highest occupied molecular orbitals (HOMOs) of $\mathrm{Au}_{3}, \mathrm{Au}_{5}, \mathrm{Au}_{6}$ and $\mathrm{Au}_{7}$ clusters, and optimized structures of the complexes formed by interaction of these clusters with $\mathrm{O}_{2}$. The numbers in black are the optimized O-O bond lengths in $\AA$, and the numbers in blue are the net charge on $\mathrm{O}_{2}$ in units of e. $\mathbf{b}$, Structures involved in the mechanism of 
disulfide formation catalyzed by a $\mathrm{Au}_{5}$ cluster. The numbers that appear next to selected bonds are the optimized bond lengths in $\AA$. The italic numbers that appear beside the arrows are the reaction and activation (denoted with \#) energies in $\mathrm{kJ} / \mathrm{mol}$ calculated for each elementary step. c, Atomic distribution of the highest occupied molecular orbital (HOMO) of structure 12. d. Stable linear RS-Au-SR units or "staple" motifs formed over $\mathrm{Au}_{5}$ and $\mathrm{Au}_{13}$ systems. The numbers in blue that appear next to to various selected atoms are net atomic charges, in units of e. Gold, Sulfur, Carbon, Oxygen and Hydrogen atoms are depicted in golden, blue, orange, red and white, respectively.

\section{Graphical Abstract}

Gold clusters with 5 to 10 atoms supported on MWCNTs are as active as enzymes in the oxidation of thiphenol to dislfide with $\mathrm{O}_{2}$. A combination of theory and experiment shows that isolated gold atoms cannot activate reactants, while larger gold nanoparticles become passivated by too strong thiolate adsorption.

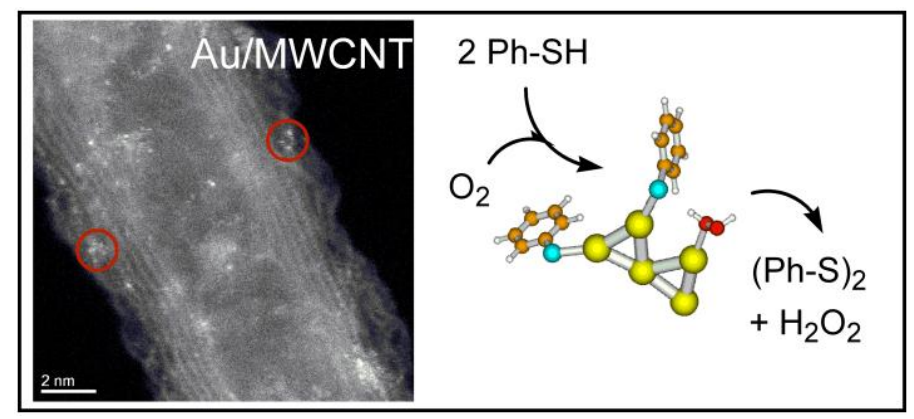

